\title{
Personalized oncogenomics
}

\author{
Steven JM Jones ${ }^{1 *}$, Janessa Laskin², Yvonne Y Li', Obi L Griffith', Jianghong An', Mikhail Bilenky', \\ Yaron S Butterfield ${ }^{1}$, Eric Chuah", Richard Corbett ${ }^{1}$, Anthony Fejes ${ }^{1}$, Simon Chan ${ }^{1}$, Nancy Liao', Katayoon Kasaian", \\ Malachi Griffith', John Yee ${ }^{3}$, Montgomery Martin", Michael Mayo', Nataliya Melnyk', Ryan D Morin?',

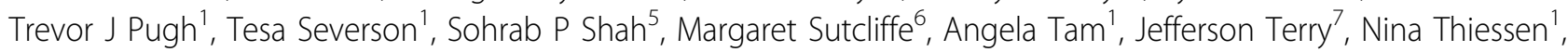 \\ Thomas Thomson ${ }^{7}$, Richard Varhol', Thomas Zeng ${ }^{1}$, Yongjun Zhao ${ }^{1}$, Richard A Moore', David G Huntsman", \\ Inanc Birol ${ }^{1}$, Martin Hirst ${ }^{1}$, Robert A Holt ${ }^{1}$, Marco A Marra ${ }^{1}$
}

From Beyond the Genome: The true gene count, human evolution and disease genomics Boston, MA, USA. 11-13 October 2010

The comprehensive genetic characterisation of human tumours promises to contribute a profound understanding of the changes that contribute to and drive the oncogenic process. In one study, we have been able to determine the oncogenic mechanisms driving a rare adenocarcinoma of the tongue and provide clinically useful information to aid in its treatment, through the determination that the cancer was driven primarily by activation of the RET pathway. The administration of RET targeting kinase inhibitors, sunitinib and sorafenib, provided tumour stabilisation for several months, after which time therapeutic resistant tumours arose. This provided us with the opportunity to identify the genetic changes associated with drug resistance allowing the observation that resistance is correlated with an apparent up-regulation of the parallel proliferative AKT pathway.

However, the complete and comprehensive analysis of a genome using this technology is still nascent and many of the software tools required to achieve this are still in development. In the analysis of tumour normal pairs, it is not clear that current levels of sampling are sufficient to identify somatic changes accurately without further validation. Likewise, the level of false negatives that confound our analyses is unclear. Such considerations will be important if this technology is to be adopted in the routine provision of personalized medicine.

${ }^{1}$ Genome Sciences Centre, BC Cancer Agency, Vancouver, BC, V5Z 4S6,

Canada

Full list of author information is available at the end of the article

\section{Author details}

${ }^{1}$ Genome Sciences Centre, BC Cancer Agency, Vancouver, BC, V5Z 4S6, Canada. ${ }^{2}$ Medical Oncology, BC Cancer Agency, Vancouver, BC, V5Z 4E6, Canada. ${ }^{3}$ Division of Thoracic Surgery, University of British Columbia, Vancouver, BC, V5Z 4E3, Canada. ${ }^{4}$ Diagnostic Imaging, BC Cancer Agency, Vancouver, BC, V5Z 4E6, Canada. ${ }^{5}$ Molecular Oncology, BC Cancer Agency, Vancouver, BC, V5Z 1L3, Canada. ${ }^{6}$ Experimental Therapeutics, BC Cancer Agency, Vancouver, BC, V5Z 1L3, Canada. ${ }^{7}$ Pathology and Laboratory Medicine, BC Cancer Agency, Vancouver, BC, V5Z 4E6, Canada.

Published: 11 October 2010

doi:10.1186/gb-2010-11-S1-I5

Cite this article as: Jones et al:: Personalized oncogenomics. Genome Biology 2010 11(Suppl 1):15.
Submit your next manuscript to BioMed Central and take full advantage of:

- Convenient online submission

- Thorough peer review

- No space constraints or color figure charges

- Immediate publication on acceptance

- Inclusion in PubMed, CAS, Scopus and Google Scholar

- Research which is freely available for redistribution

Submit your manuscript at www.biomedcentral.com/submit
Biomed Central 